Ciência e Natura, Santa Maria, v. 37 n. 4 set-dez. 2015, p. 451-470

Revista do Centro de Ciências Naturais e Exatas - UFSM

ISSN impressa: 0100-8307 ISSN on-line: 2179-460X

\title{
ESTUDO DE ZONEAMENTO DO CONFORTO TÉRMICO HUMANO PARA O RIO GRANDE DO SUL: A INSERÇÃO DE ANOS-PADRÃO COMO PROPOSTA METODOLÓGICA
}

\author{
Zoning study of human thermal comfort for the rio grande do sul: the integration of years as \\ standard proposed methodology \\ João Paulo Assis Gobo ${ }^{1}$, Emerson Galvani ${ }^{1}$, Cassio Arthur Wollmann² ${ }^{2}$ Maria Cristina Celuppi ${ }^{3}$ \\ Universidade de São Paulo, USP, SP, Brasil. \\ Universidade Federal de Santa Maria, UFSM, Santa Maria, RS, Brasil. \\ Universidade Luterana do Brasil - ULBRA, Brasil.
}

\begin{abstract}
Resumo
A presente pesquisa avaliou as condições de conforto térmico nas escalas regional e sub-regional no estado do Rio Grande do Sul, com base no zoneamento do conforto térmico humano para anos-padrão classificados como mais chuvoso, menos chuvoso e habitual. Para tal, utilizou-se da base de dados climáticos do Instituto Nacional de Meteorologia (INMET), sob a qual procedeu-se a construção do banco de dados, no qual foram atribuídos os índices de Temperatura Efetiva com Vento (TEv), para as estações de outono e inverno, e o índice de Temperatura Resultante (TR) para as estações de primavera e verão. As faixas de sensação térmica foram definidas a partir das classes elaboradas por Fanger (1972) e adaptadas para São Paulo, SP por Maia e Gonçalves (2002). Após digitalização dos dados, verificou-se que estações do outono, verão e primavera mostraram-se como sendo as estações em que a determinação das faixas de sensação térmica na área de estudo apresentaram-se fortemente influenciadas pelos controles climáticos, tais como altitude, continentalidade, maritimidade e latitude, enquanto a estação de inverno apresentou forte influência da dinâmica atmosférica regional.
\end{abstract}

Palavras-chave: conforto térmico humano; zoneamento; anos-padrão.

\begin{abstract}
This study concerns to evaluate the thermal comfort conditions in the regional and sub-regional climatic scales in the state of Rio Grande do Sul, based on the human thermal comfort zoning for pattern-years ranked as rainier, rainy and less one. To find those results, it was necessary to use a climatic database of the National Institute of Meteorology (INMET), under which it undertook the construction of the database, which indexes Effective Temperature with Wind (VTE) have been allocated for autumn and winter seasons, and the index of Resultant Temperature (RT) for the spring and summer seasons only one. The tracks of thermal sensation were defined from the classes developed by Fanger (1972) and adapted to Sao Paulo capital for Maia and Gonçalves (2002). After scanning data, it was possible to found that in autumn, summer and spring seasons, these ones showed up as the seasons in which the determination of thermal sensation tracks in the study area were strongly influenced by climatic controls, such as altitude, continentality and maritimidade, meanwhile the winter season showed a strong influence of regional atmospheric circulation and dynamic.
\end{abstract}

Keywords: human thermal comfort; zoning; standard years. 


\section{INTRODUÇÃO}

Os seres humanos têm conhecimento de que o tempo e o clima interferem na saúde e no bem-estar desde os trabalhos de Hipócrates a 2.500 anos, onde este escrevera sobre as diferenças regionais do clima e sua relação com estados de saúde, febre, humor e vários distúrbios psicológicos (MATZARAKIS; MAYER, 1997).

De acordo com Monteiro e Alucci (2005; 2007 e 2010) a sensação de conforto térmico está associada com o ritmo de troca de calor entre o corpo humano e o meio ambiente. Neste sentido, o desempenho durante qualquer atividade deve ser otimizado, desde que o ambiente propicie condições de conforto e que sejam evitadas sensações desagradáveis. Estas sensações são funções não só das condições ambientais, mas também da capacidade de aclimatização ao meio ambiente, dos hábitos alimentares, das atividades, da altura, do peso, do tipo de roupa de cada indivíduo, e até mesmo da idade e sexo (GOLDEN et al., 2008).

Quando a temperatura e a umidade são elevadas, os indivíduos submetem-se a uma situação de considerável estresse térmico. O calor extremo, bem como o frio extremo, podem ter um impacto maior sobre a saúde humana do que qualquer outro tempo extremo, especialmente entre os idosos (GOLDEN et al., 2008).

Temperaturas altas e muito reduzidas, podem aumentar o risco de morbidade e mortalidade, principalmente em ambientes onde a faixa de conforto térmico não apresenta boa abrangência climática, caracterizando menor tolerância da população a estas adversidades biometeorológicas (CHANGNON, et al., 2000).

Percebe-se, portanto, que o bem-estar de um indivíduo, do ponto de vista climático, está diretamente ligado às características ambientais em que este está inserido. Sendo assim, atributos geográficos como a altitude, a latitude, uso do solo, a continentalidade e a maritimidade determinam o clima de um determinado local e consequentemente a existência, ou não, de conforto térmico neste ambiente.

Sendo assim, o presente trabalho buscou verificar os padrões de conforto térmico no estado do Rio Grande do Sul por meio de um zoneamento do conforto térmico humano para anos-padrão representativos de mais chuvoso, menos chuvoso e habitual, a fim de se identificar os pontos de maior e menor estresse térmico na área de estudo em cada uma das quatro estações do ano.

\section{CARACTERIZAÇÃO DA ÁREA DE ESTUDO}

A área de estudo selecionada para esta pesquisa corresponde ao Estado do Rio Grande do Sul, localizado no extremo sul do Brasil, entre as coordenadas geográficas: $27^{\circ}$

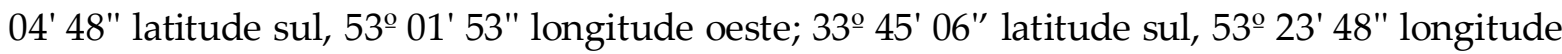

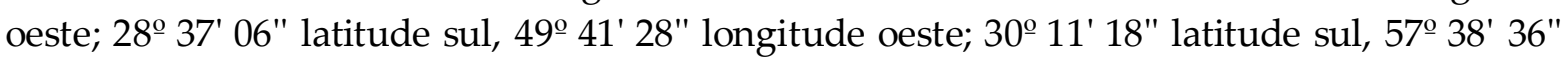
longitude oeste (IBGE, 2014).

No que se refere às características naturais, o Rio Grande do Sul atualmente está dividido em cindo unidade geomorfológicas em relação à compartimentação geomorfológica do Estado, que é fortemente condicionada pela geologia regional, são elas: Planalto Meridional, Planície Costeira, Escudo Sul-Rio-grandense, Depressão Central e Cuestas do Haedo (Figura 1) (SEMA/RS, 2010).

As altitudes máximas ultrapassam a cota de 1200 metros acima do nível do mar principalmente no limite com o Estado de Santa Catarina, no Planalto da Bacia do Paraná, e 
constitui-se num grande controle climático, principalmente na variação das precipitações e da temperatura do ar (Figura 2) (SEMA/RS, 2010).
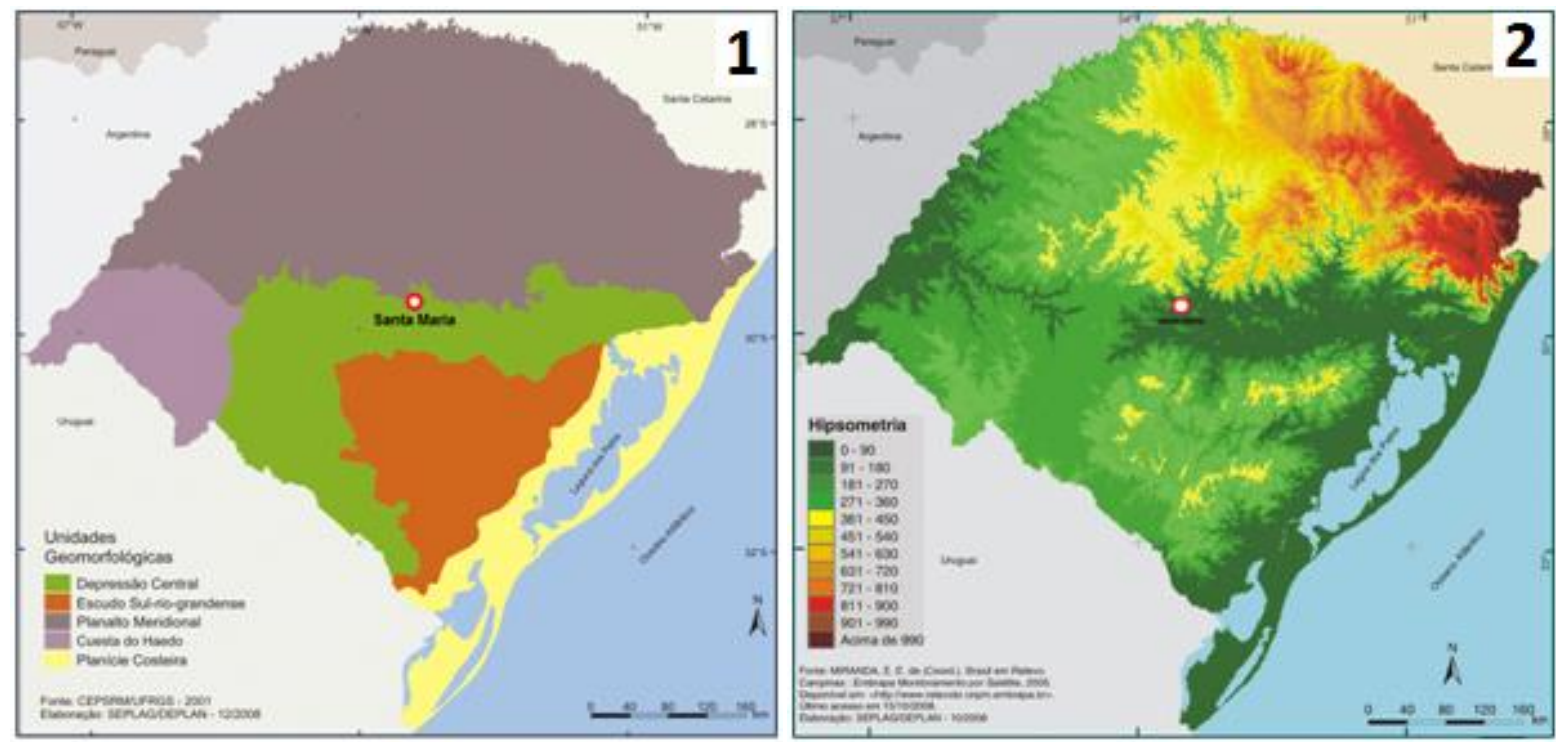

Figura 1: Mapa das unidades Geomorfológicas do Rio Grande do Sul. Figura 2: Mapa hipsométrico do Rio Grande do Sul. Fonte: Atlas Socioeconômico do Rio Grande do Sul (2010).

\section{MATERIAIS E MÉTODOS}

Para o desenvolvimento da pesquisa, foram utilizados dados meteorológicos referentes à temperatura do ar, à umidade relativa do ar e à velocidade do vento, para uma série histórica de 30 anos, correspondentes aos anos compreendidos entre 1981 e 2010, de 23 estações meteorológicas da rede de estações do Instituto Nacional de Meteorologia (INMET).

$\mathrm{Na}$ escolha de anos-padrão adotou-se a análise rítmica, técnica proposta por Monteiro (1969, 1971, 2000), como subsídio para investigação dos tipos de tempo, em sua sucessão habitual e extrema, condição que configura o ritmo climático (MOURA; ZANELLA, 2012).

Assim, segundo o conceito de clima proposto por Sorre (1951), com a noção de ritmo climático, a chuva é o elemento climático de maior variação interanual, refletindo de maneira mais adequada a noção de ritmo, em que há "o encadeamento, sucessivo e contínuo, dos estados atmosféricos e suas articulações no sentido de retorno dos mesmos estados" (MONTEIRO, 1976: p.30).

De posse dos dados pluviométricos mensais do período, foi calculada a média de precipitação para o Rio Grande do Sul para a série de 30 anos de dados, e foram caracterizados como ano-padrão habitual para o Rio Grande do Sul os anos nos quais os totais pluviométricos registrados encontravam-se no intervalo de $1300 \mathrm{~mm}$ a $1800 \mathrm{~mm}$ anuais $(2007,1749,6 \mathrm{~mm})$, os mais chuvosos com totais superiores a 1800mm (2002, $2591,1 \mathrm{~mm})$ e os anos-padrão menos chuvosos aqueles de totais anuais de precipitação inferiores a 1300mm (2004, 1064,5mm) (RUOSO, et. al., 2006).

Selecionou-se um mês representativo de cada estação do ano para ser estudado, determinando-se, assim, janeiro como o mês representativo do verão, abril como mês representativo do outono, julho como o do inverno e outubro como o da primavera. 
Para o cálculo dos índices de conforto térmico, calculou-se o conforto térmico para cada um dos três anos-padrão selecionados $(2002,2004$ e 2007) por meio do Índice de Temperatura Resultante TR (Co $)$ (MISSENARD, 1948), para os meses representativos de primavera e verão, com o uso da seguinte equação:

$$
\mathrm{TR}=\mathrm{Ts}-0,4(\mathrm{Ts}-10)(1-\mathrm{UR} / 100)
$$

\section{Equação 1:}

Onde: TR é a temperatura resultante $\left({ }^{\circ} \mathrm{C}\right)$; Ts é a temperatura do ar (bulbo seco) $\left({ }^{\circ} \mathrm{C}\right)$; UR é a umidade relativa do ar (\%).

Para os meses representativos de outono e inverno, utilizou-se o Índice de Temperatura Efetiva com Vento TEv (Cํ) (SUPING et. al., 1992), dado pelo cálculo:

$$
\text { TEv }=37-\frac{(37-T)}{\left[0,68-0,0014 R H+\frac{1}{1,76+1,4 v^{0,75}}\right]}-0,29 T\left(1-\frac{R H}{100}\right) \quad \text { Equação 2: }
$$

Onde: $\mathrm{T}$ é a temperatura do ar em ${ }^{\circ} \mathrm{C}$; $\mathrm{RH}$ é a umidade relativa em $\%$; $v$ é a velocidade do vento em $\mathrm{m} / \mathrm{s}$ (medida a 10 metros de altura); TEv é a temperatura efetiva em função do vento em ${ }^{\circ} \mathrm{C}$.

Devido ao Rio Grande do Sul não possuir uma classificação das zonas de conforto térmico adequadas aos padrões climáticos do Estado, a presente pesquisa utilizou-se da Classificação Térmica desenvolvida por Maia e Gonçalves (2002) para espaços urbanos abertos na cidade de São Paulo, com base nas condições de conforto térmico estabelecido por Fanger (1972) (Quadro 1).

Quadro 1 - Classes de conforto térmico

\begin{tabular}{ccc}
\hline Tev $\left(\mathbf{C}^{\mathbf{0}}\right)$ & Sensação Térmica & Grau de Estresse Fisiológico \\
\hline$<13$ & Muito Frio & Extremo Estresse ao Frio \\
\hline $13-16$ & Frio & Tiritar \\
\hline $16-19$ & Frio Moderado & Ligeiro Resfriamento do Corpo \\
\hline $19-22$ & Ligeiramente Frio & Vasoconstrição \\
\hline $22-25$ & Confortável & Neutralidade Térmica \\
\hline $25-28$ & Ligeiramente Quente & Ligeiro Suor e Vasodilatação \\
\hline $28-31$ & Quente Moderado & Suando \\
\hline $31-34$ & Quente & Suor em Profusão \\
\hline$>34$ & Muito Quente & Falha na Termorregulação \\
\hline & Fonte: Maia e Gonçalves (2002). \\
& Org.: GOBO, J. P. A. (2014).
\end{tabular}

A seguir foram calculados a porcentagem de ocorrência de determinada classe de conforto/desconforto térmico para a área de estudo e, por fim, os arquivos foram exportados para o software ARCGIS 3.2, onde atribuíram-se as classes interpretativas para a Sensação Térmica e fez-se a edição final dos mapas e a sobreposição destes, totalizando o cruzamento dos dados de todos os mapas dos três anos-padrão (2002, 2004 e 2007). 


\section{ANÁLISE DOS RESULTADOS}

\section{Primavera (Outubro) Ano-Padrão Mais Chuvoso (2002)}

O mapa do zoneamento do conforto térmico para a primavera do ano-padrão mais chuvoso (Figura 3A) é característico por classificar apenas três faixas de sensação térmica no território do Rio Grande do Sul, sendo "Frio" (8,7\% do território), "Frio Moderado" (73,9\% do território) e "Ligeiramente Frio" (17,4\%do território).

Nota-se que a maior parte do Estado está representado pela faixa de sensação térmica de "Frio Moderado" com TR médio variando entre $16^{\circ} \mathrm{C}$ e $19^{\circ} \mathrm{C}$, enquanto parte da serra do nordeste apresenta-se na faixa de "Frio", em que a média do índice TR varia entre $13^{\circ} \mathrm{C}$ e $16^{\circ} \mathrm{C}$. A faixa de sensação térmica correspondente a "Ligeiramente Frio" fica restrita ao noroeste do Estado, próximo à fronteira com a Argentina, no vale do rio Uruguai.

Sartori (2003, p. 71) afirma que "...os fluxos de origem intertropical tendem a aumentar seu valor de frequência na região pelo enfraquecimento da intensidade dos fluxos polares, motivado pela redução dos gradientes térmicos latitudinais e pelo aquecimento do hemisfério", o que pode ser interpretado como um padrão característico desta estação de transição entre o inverno e o verão, refletindo na distribuição das faixas de conforto térmico espacializadas no estado.

\section{Primavera (Outubro) Ano-Padrão Menos Chuvoso (2004)}

Diferentemente do zoneamento do conforto térmico para a primavera do anopadrão mais chuvoso (2002), o zoneamento para a primavera do ano-padrão menos chuvoso (2004), apresenta uma maior homogeneidade no padrão das faixas de sensação térmica classificadas (Figura 3B).

Há apenas duas faixas classificadas no território do Rio Grande do Sul, sendo estas as de "Frio" (21,7\%) e "Frio Moderado" (78,3\% do território), correspondentes ao índice TR entre $13^{\circ} \mathrm{C}$ e $16^{\circ} \mathrm{C}$, e $16^{\circ} \mathrm{C}$ a $19^{\circ} \mathrm{C}$, respectivamente.

A faixa de sensação térmica de "Frio" está restrita às regiões do nordeste do planalto meridional, bem como do extremo sul do Estado, enquanto a faixa de "Frio Moderado" encontra-se distribuída pela maior parte do território, ocupando as regiões do litoral médio e norte, bem como a região central, o oeste, o vale do rio Uruguai e a maior parte do planalto.

\section{Primavera (Outubro) Ano-Padrão Habitual (2007)}

O zoneamento da primavera do ano-padrão habitual (2007) mostrou-se mais quente que os demais zoneamentos para a mesma estação do ano, nos outros dois anos-padrão observados (Figura 3C).

Há três faixas de sensação térmica classificadas no zoneamento da primavera de 2007, sendo elas as condições de "Frio" (8,7\% da área total), "Frio Moderado" (60,9\% da área total) e "Ligeiramente Frio" (30,4\% da área total). Destas, a faixa de "Frio Moderado", com valores médios de TR oscilando entre $16^{\circ} \mathrm{C}$ e $19^{\circ} \mathrm{C}$, ocupa a maior parte do território do Rio Grande do Sul, prevalecendo sobre praticamente toda a metade sul do Estado, a região central, parte do oeste, do planalto e da serra de nordeste. 
A faixa de "Frio", com valores médios de $\mathrm{TR}$ entre $13^{\circ} \mathrm{C}$ e $16^{\circ} \mathrm{C}$, fica restrita ao extremo sul do Estado e às áreas mais elevadas da serra de nordeste, onde as temperaturas são as mais baixas em todos os zoneamentos já realizados anteriormente.

Por fim, a faixa de sensação térmica de "Ligeiramente Frio", com índice TR entre $19^{\circ} \mathrm{C}$ e $22^{\circ} \mathrm{C}$, abrange apenas a região noroeste do Estado, limitando-se ao setor do vale do rio Uruguai, região esta que, nos demais zoneamentos realizados nesta pesquisa, apresentou os valores de TR e TEv mais elevados dentre todos os da série estudada.

\section{Verão (Janeiro) Ano-Padrão Mais Chuvoso (2002)}

No zoneamento do conforto térmico para o verão do ano-padrão mais chuvoso (Figura 4A) assim como no zoneamento da primavera também se verificam três faixas de sensação térmica classificadas, que são "Frio Moderado" (13\% do território), "Ligeiramente Frio" (47,8\% do território) e Confortável" (39,2\% do território).

O zoneamento do verão é o único que apresenta a faixa de sensação térmica "Confortável" classificada dentre as demais estações do ano de 2002 zoneadas. A faixa em questão, com índice TR médio entre $22^{\circ} \mathrm{C}$ e $25^{\circ} \mathrm{C}$, compreende todo o vale do rio Uruguai, desde o norte do Estado até o oeste. Também se verifica a faixa de sensação térmica "Confortável" em parte da região central do Estado, na região metropolitana de Porto Alegre e no litoral médio.

Esse padrão de distribuição da zona de conforto térmico no território do estado está fortemente associado a atributos climáticos tais como a continentalidade, a maritimidade e a altitude destas regiões de abrangência da faixa de sensação térmica em questão.

A faixa de sensação térmica "Frio Moderado", com índice TR médio entre $16^{\circ} \mathrm{C}$ e $19^{\circ} \mathrm{C}$, restringe-se à região da serra de nordeste e a parte do planalto, sendo essas regiões as mais altas do estado, o que de certa forma auxilia a manutenção das temperaturas médias amenas.

Wollmann e Sartori (2009), já ressaltavam para uma maior atuação dos sistemas de origem extratropical durante o verão de um ano-padrão mais chuvoso no estado. Esta atuação de sistemas extratropicais é que deram à estação elevados totais pluviométricos.

A maior parcela do Rio Grande do Sul, no entanto, corresponde à faixa de sensação térmica "Ligeiramente Frio", representada por índice TR médio entre $19^{\circ} \mathrm{C}$ e $22^{\circ} \mathrm{C}$. Essa faixa abrange toda a metade sul do Estado bem como partes da região central, da serra do nordeste e do planalto.

\section{Verão (Janeiro) Ano-Padrão Menos Chuvoso (2004)}

No zoneamento do verão do ano-padrão menos chuvoso (Figura 4B), notam-se zonas de faixa de sensação térmica "Confortável" (34,8\% do território) menores em relação ao verão do ano-padrão mais chuvoso (2002).

O zoneamento dessa estação para o ano menos chuvoso apresenta, ainda, faixas de sensação térmica de "Ligeiramente Frio" (47,8\% do território) e "Frio Moderado" (17,4\% do território) classificadas no território do Rio Grande do Sul, sendo a faixa de "Ligeiramente Frio" a predominante, com índice TR médio oscilando entre $19^{\circ} \mathrm{C}$ e $22^{\circ} \mathrm{C}$, enquanto a faixa de "Frio Moderado", com índice TR médio entre $16^{\circ} \mathrm{C}$ e $19^{\circ} \mathrm{C}$, restrita às regiões mais elevadas da serra de nordeste.

A faixa de sensação térmica "Confortável", com índice TR médio variando entre $22^{\circ} \mathrm{C}$ e $25^{\circ} \mathrm{C}$, abrange parte da região metropolitana de Porto Alegre e todo o vale do rio 
Uruguai, no oeste do Estado, sendo essas regiões caracterizadas por altitudes que variam entre $0 \mathrm{~m}$ e $200 \mathrm{~m}$, onde é forte a influência da maritimidade e da continentalidade.

A pouca cobertura de nuvens em um ano tido como menos chuvoso é causada, segundo Wollmann e Sartori (2009), pela participação das massas de ar de origem polar descaracterizadas que dominam praticamente durante toda a estação.

A inclusão do conforto térmico no estado dentro das faixas de "Frio Moderdo", "Ligeiramente Frio" e "Confortável" em plena estação mais quente do ano, deve-se, em parte, a predominância dos sistemas atmosféricos extratropicais sobre os de origem tropical no Rio Grande do Sul, mesmo durante o verão (WOLLMANN; SARTORI, 2009).

\section{Verão (Janeiro) Ano-Padrão Habitual (2007)}

Observando-se o mapa do zoneamento do conforto térmico para o verão do anopadrão habitual (Figura 4C), pode-se constatar um domínio mais abrangente das faixas mais quentes de sensação térmica, em relação aos demais verões observados anteriormente.

De fato, das três faixas de sensação térmica classificadas, a faixa "Confortável" $\left(65,2 \%\right.$ do território), com índice TR entre $22^{\circ} \mathrm{C}$ e $25^{\circ} \mathrm{C}$, é a que predomina no território do Rio Grande do Sul nesse zoneamento. Ela ocupa boa parte do planalto, a região oeste do Estado, a região central, do litoral e da metade sul do Rio Grande do Sul. Novamente há influência da continentalidade no oeste do estado e da maritimidade próximo ao litoral, determinando a amenização da situação de conforto térmico, associado as altitudes pouco elevadas dessas regiões.

As demais faixas de sensação térmica classificadas foram a de "Ligeiramente Frio" (30,8\% do território) e "Frio Moderado" (4\% do território), com índices TR variando entre $19^{\circ} \mathrm{C}$ e $22^{\circ} \mathrm{C}$, e $16^{\circ} \mathrm{C}$ e $19^{\circ} \mathrm{C}$, respectivamente. Destas, a faixa de "Ligeiramente Frio" foi classificada no extremo sul do Rio Grande do Sul, na região da campanha, próxima à fronteira com o Uruguai, em um núcleo na serra de sudeste (escudo cristalino), e em parte do litoral norte e da serra de nordeste.

A faixa de "Frio Moderado" ficou restrita a um pequeno núcleo na região dos campos de cima da serra, na serra de nordeste próximo à divisa entre os Estados do Rio Grande do Sul e de Santa Catarina.

Diferentemente do ano mais chuvoso e menos chuvoso, o ano habitual apresenta a maior parte do território do estado dentro da faixa de sensação térmica de confortável, o que, segundo Wollmann e Sartori (2009), pode ser interpretado pelo fato de que o que diferencia o verão das demais estações do ano no Rio Grande do Sul é a descaracterização mais rápida dos sistemas atmosféricos polares que dominam no Estado.

Os autores chamam atenção para o fato de que em anos-padrão habitual, diferentemente de anos mais ou menos chuvosos no estado, os sistemas atmosféricos de origem intertropical Massa Tropical Continental e Massa Tropical Atlântica (MTC e MTA) são mais frequentes no verão, exercendo maior controle na dinâmica atmosférica regional em anos-padrão habituais (WOLLMANN; SARTORI, 2009). 


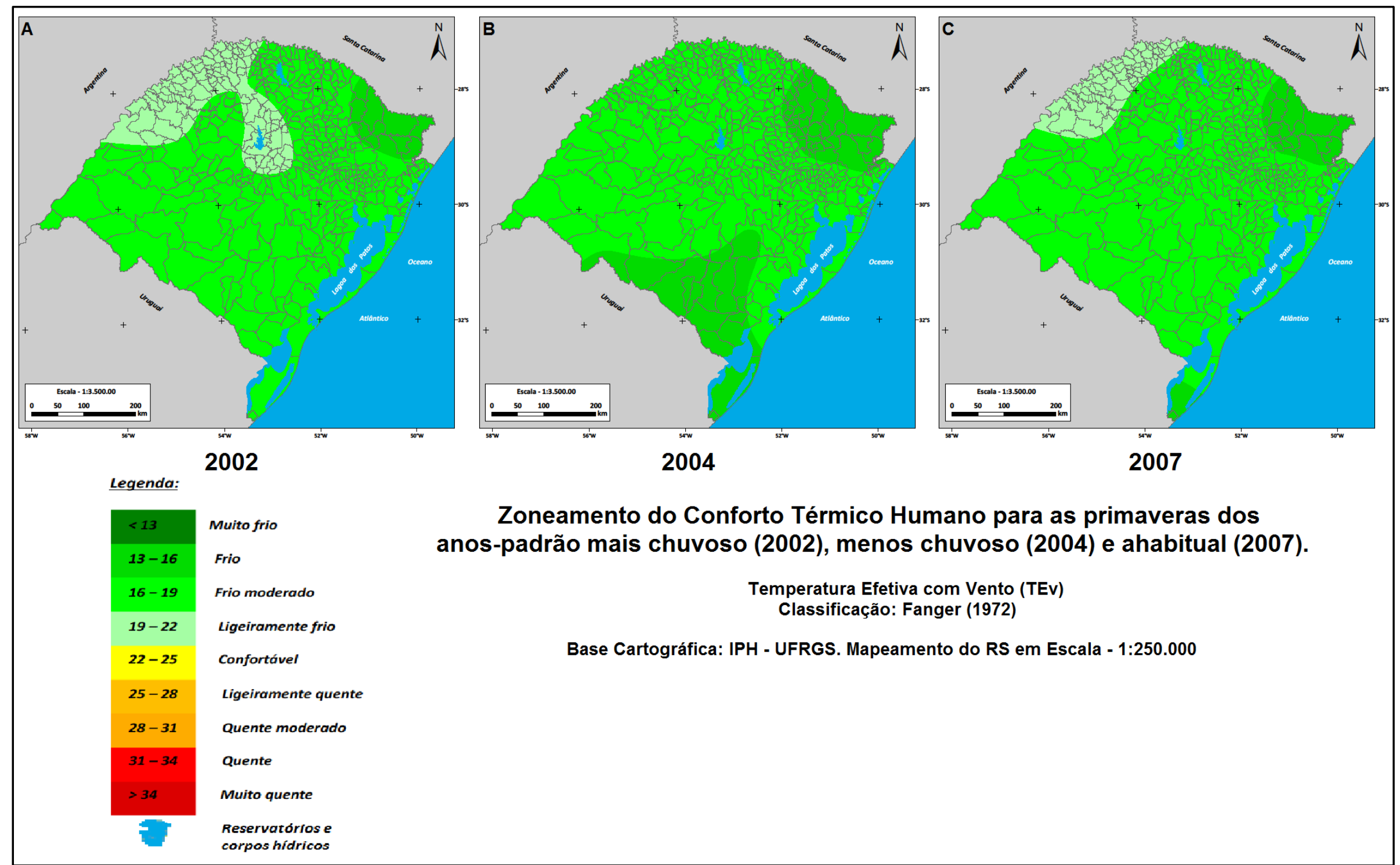

Figura 3: Mapas do Zoneamento do Conforto Térmico para as primaveras dos anos-padrão 2002, 2004 e 2007. Org.: GOBO, J. P. A. (2014). 


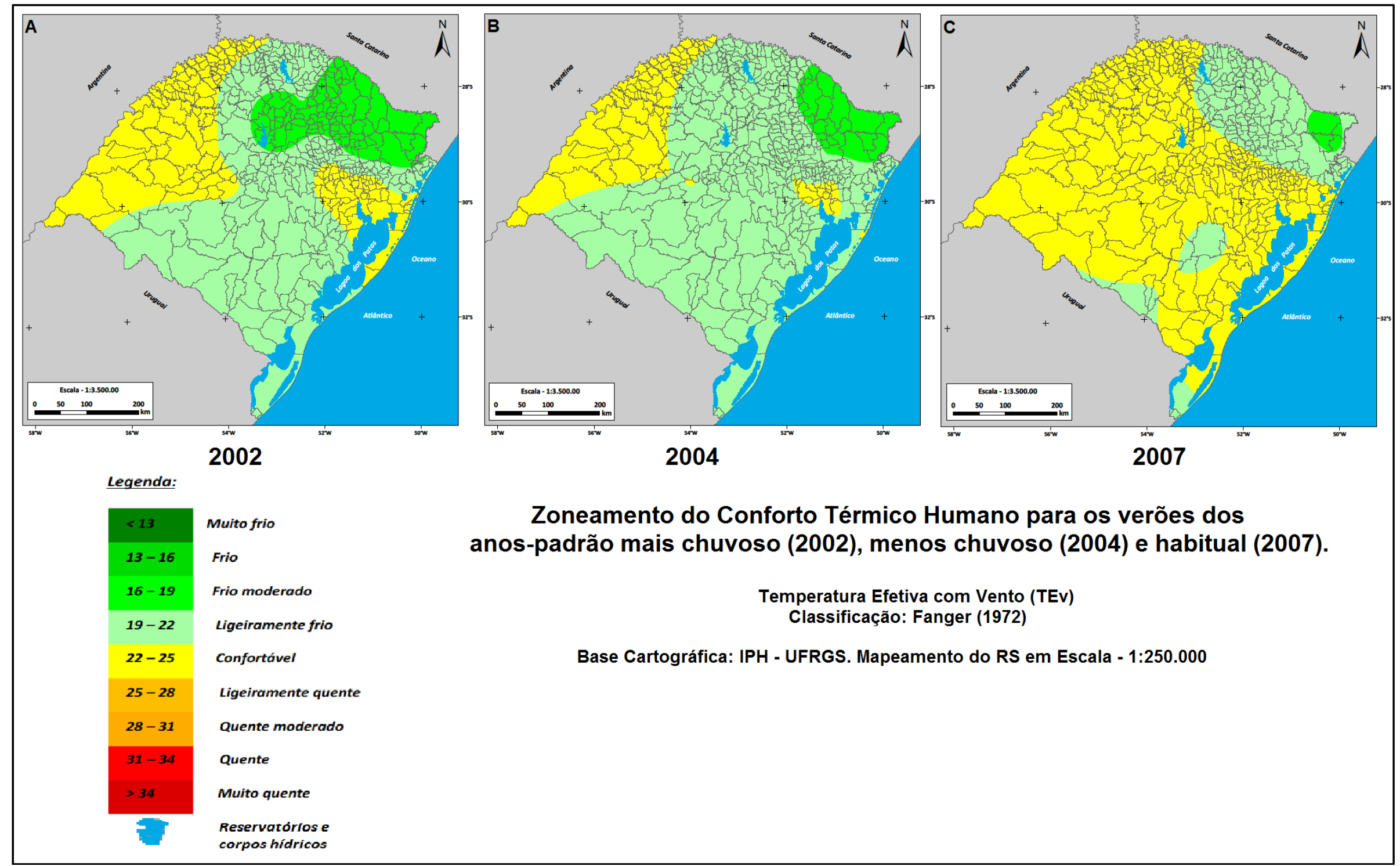

Figura 4: Mapas do Zoneamento do Conforto Térmico para o verão dos anos-padrão 2002, 2004 e 2007. Org.: GOBO, J. P. A. (2014). 


\section{Outono (Abril) Ano-Padrão Mais Chuvoso (2002)}

Para Monteiro (1963) no outono as Frentes Polares (FPA) começam a se tornar mais intensas devido ao resfriamento do hemisfério, intensificando a formação das massas de ar como a Massa Polar Atlântica (MPA) e a Massa Tropical Atlântica, gerando Frentes Quentes (FQ) e intensa Ciclogênese na Região Sul, o que promove maiores acumulados de chuva nesse período do ano, o que se reflete na disposição das faixas de conforto térmico espacializadas no estado.

O outono do ano-padrão mais chuvoso (Figura 5A) apresenta as quatro faixas de sensação térmica de desconforto por frio classificadas, sendo elas "Muito Frio" (17,4\% da área total do estado), "Frio" (34,8\% da área total), "Frio Moderado" (34,8\% da área total) e "Ligeiramente Frio" (13\% da área total).

No outono do ano padrão mais chuvoso, as regiões mais elevadas da serra do nordeste bem como as regiões do extremo sul do Estado e da fronteira sul com o Uruguai apresentam-se classificadas na faixa de sensação térmica de "Muito Frio", com índice TEv médio menor que $13^{\circ} \mathrm{C}$. Essas regiões são caracterizadas pela influência determinante do vento nessa época do ano, o que auxilia a redução da faixa de conforto térmico humano observado.

Nota-se também no mapa de zoneamento do outono uma tendência à suavização das faixas de sensação térmica, à medida que observamos a região central do estado a partir da serra de nordeste e do extremo sul, estando a faixa de "Frio Moderado" e "Ligeiramente Frio" correspondentes ao índice médio de $\mathrm{TEv}$ entre $16^{\circ} \mathrm{C}$ e $19^{\circ} \mathrm{C}$, e $19^{\circ} \mathrm{C}$ e $22^{\circ} \mathrm{C}$, respectivamente, localizadas na região central do estado, com a faixa de "Frio Moderado" estendendo-se pelo vale do rio Uruguai e parte do planalto.

A faixa de sensação térmica "Frio", com índice TEv médio variando entre $13^{\circ} \mathrm{C}$ e $16^{\circ} \mathrm{C}$, fica nas zonas intermediárias entre a faixa de "Muito Frio" e "Frio Moderado", ocupando partes do planalto e da região da campanha, bem como do extremo sul do Estado.

\section{Outono (Abril) Ano-Padrão Menos Chuvoso (2004)}

O outono do ano-padrão menos chuvoso (Figura 5B) é caracterizado pela homogeneidade da classificação das faixas de sensação térmica, assim como a primavera do mesmo ano-padrão.

Notam-se, no zoneamento do outono, três faixas de sensação térmica classificadas, sendo estas a de "Muito Frio" (39,1\% da área total do estado), "Frio" (52,2\% da área total) e "Frio Moderado" (8,7\% da área total).

A faixa de sensação térmica de "Muito Frio", caracterizada por índices de TEv médio abaixo de $13^{\circ} \mathrm{C}$, cobre toda a serra do nordeste e parte do planalto e o extremo sul do Estado, prolongando-se até próximo à região central.

No que diz respeito à faixa de sensação térmica de "Frio", com índice TEv médio entre $13^{\circ} \mathrm{C}$ e $16^{\circ} \mathrm{C}$, ela abrange toda a região central do Estado, o litoral médio e norte, bem como a região oeste, incluindo parte da campanha e do planalto.

\section{Outono (Abril) Ano-Padrão Habitual (2007)}

Mais uma vez, como nos demais zoneamentos do conforto térmico para o outono dos anos-padrão selecionados, o outono de 2007 (ano-padrão habitual) (Figura 5C) mostrou-se bastante homogêneo, com três faixas de sensação térmica classificadas, porém com o predomínio de duas grandes faixas. 
Apesar do outono do Rio Grande do Sul ser a estação mais chuvosa, apresentando índice percentual de precipitação acima de 25\% (SARTORI, 1993), observou-se no zoneamento, tanto do ano menos chuvoso quanto do ano habitual, um resfriamento amplamente distribuído na espacialização das faixas de sensação térmica.

Foram classificadas as faixas de sensação térmica de "Muito Frio" (30,4\% da área total do estado), "Frio" (47,8\% da área total) e "Frio Moderado" (21,8\% da área total), sendo que a faixa de "Frio", com índice TEv entre $13^{\circ} \mathrm{C}$ e $16^{\circ} \mathrm{C}$, praticamente divide o Estado entre duas zonas de "Muito Frio", estas com índice TEv médio abaixo de $13^{\circ} \mathrm{C}$.

A faixa de "Muito Frio" abrange a serra de nordeste e uma pequena faixa do planalto, bem como a metade sul do Estado, com parte do litoral sul e da campanha. Já a faixa de "Frio" divide as duas zonas de "Muito Frio", ocupando todo o litoral médio e norte do Rio Grande do Sul assim como a região central do Estado, o oeste e o planalto.

Há ainda um núcleo de "Frio Moderado" classificado em torno da região metropolitana de Porto Alegre, onde, tal como na região do vale do rio Uruguai, verificamse os valores mais elevados de TR e TEv da série estudada.

\section{Inverno (Julho) Ano-Padrão Mais Chuvoso (2002)}

No zoneamento do inverno do ano-padrão mais chuvoso (Figura 6A), verifica-se apenas uma faixa de sensação térmica classificada, abrangendo todo o território do Rio Grande do Sul. A faixa em questão é a de "Muito Frio" (100\% da área total do estado) e representa valores de TEv menores que $13^{\circ} \mathrm{C}$.

Apesar de ocorrerem episódios de temperaturas elevadas em determinados períodos, mesmo no inverno, a média geral das temperaturas no Rio Grande do Sul é baixa devido aos valores extremos identificados nas regiões mais frias do Estado, como a serra do nordeste, parte do planalto, a campanha e o extremo sul. Assim, os valores de TEv tendem a manter-se baixos devido ao vento que intensifica, ainda mais, a sensação de extremo desconforto por frio. Porém, em anos de El Niño, onde há maior concentração de umidade no estado durante o inverno, existe forte tendência das temperaturas médias e mínimas serem superiores às dos anos habituais no outono e início do inverno (BERLATO; FONTANA, 2003).

O percentual da área do Rio Grande do Sul zoneada na faixa de sensação térmica de "Muito Frio", pode estar relacionado com os padrões climáticos do inverno sul-riograndense, que caracteriza-se pelo amplo predomínio dos tipos de tempo associados ao domínio das massas de ar polares, sobretudo pela Massa Polar Atlântica a qual é responsável pelo abaixamento das temperaturas máximas e mínimas diárias e pela estabilidade do tempo atmosférico (SARTORI, 1993).

\section{Inverno (Julho) Ano-Padrão Menos Chuvoso (2004)}

O zoneamento do conforto térmico para o inverno do ano-padrão menos chuvoso (Figura 6B), no Rio Grande do Sul, mostrou-se semelhante ao do ano-padrão mais chuvoso, apresentando novamente homogeneidade nas faixas de sensação térmica classificadas, com o predomínio da faixa de "Muito Frio" (100\% da área total do estado), que apresenta valores médios de TEv menores que $13^{\circ} \mathrm{C}$.

Costa et al. (2008) estudaram a "Ocorrência de Ondas de Frio na Região de Santa Maria-RS" entre os meses de abril e outubro dos anos de 1968 a 2004 e chegaram à conclusão de que a ocorrência deste fenômeno na região não é incomum e as maiores ocorrências anuais do fenômeno foram verificadas durante os meses de inverno (junho, 
julho e agosto), devido à maior regularidade de atuação e domínio da Massa Polar Atlântica com trajetória marítima e continental, sendo esta última de maior importância para a formação do fenômeno (COSTA et. al. 2008; SARTORI, 1993). Esse padrão de ondas de frio intensas e frequentes durante o inverno do estado, aumenta ainda mais a sensação térmica de "Muito Frio", que já é comum nessa época do ano, fazendo com que o desconforto térmico por frio seja ainda mais intenso.

\section{Inverno (Julho) Ano-Padrão Habitual (2007)}

No zoneamento do inverno do ano-padrão habitual (Figura 6C), novamente verifica-se apenas uma faixa de sensação térmica classificada abrangendo todo o território do Rio Grande do Sul. A faixa em questão é a de "Muito Frio" (100\% da área total do estado) e representa valores de TEv menores que $13^{\circ} \mathrm{C}$.

O mesmo pode ser observado nos zoneamentos dos invernos dos demais anospadrão anteriormente analisados, o que denota uma influência diferente, do ponto de vista climatológico, nos elementos e atributos climáticos envolvidos dos demais zoneamentos.

Assim, com base na resposta do conforto térmico humano no inverno dos três anospadrão, é possível observar a não influência direta de atributos climáticos tais como a altitude, a continentalidade e a maritimidade na definição das faixas de conforto espacializadas. Isso deve-se pela presença de apenas uma faixa de conforto (Muito Frio) ter sido observada no zoneamento para os três anos, o que pode ser atribuído a maior influência dos sistemas atmosféricos predominantes nesta época do ano, como foram observado por Costa et. al. (2008) e Sartori (1993). 


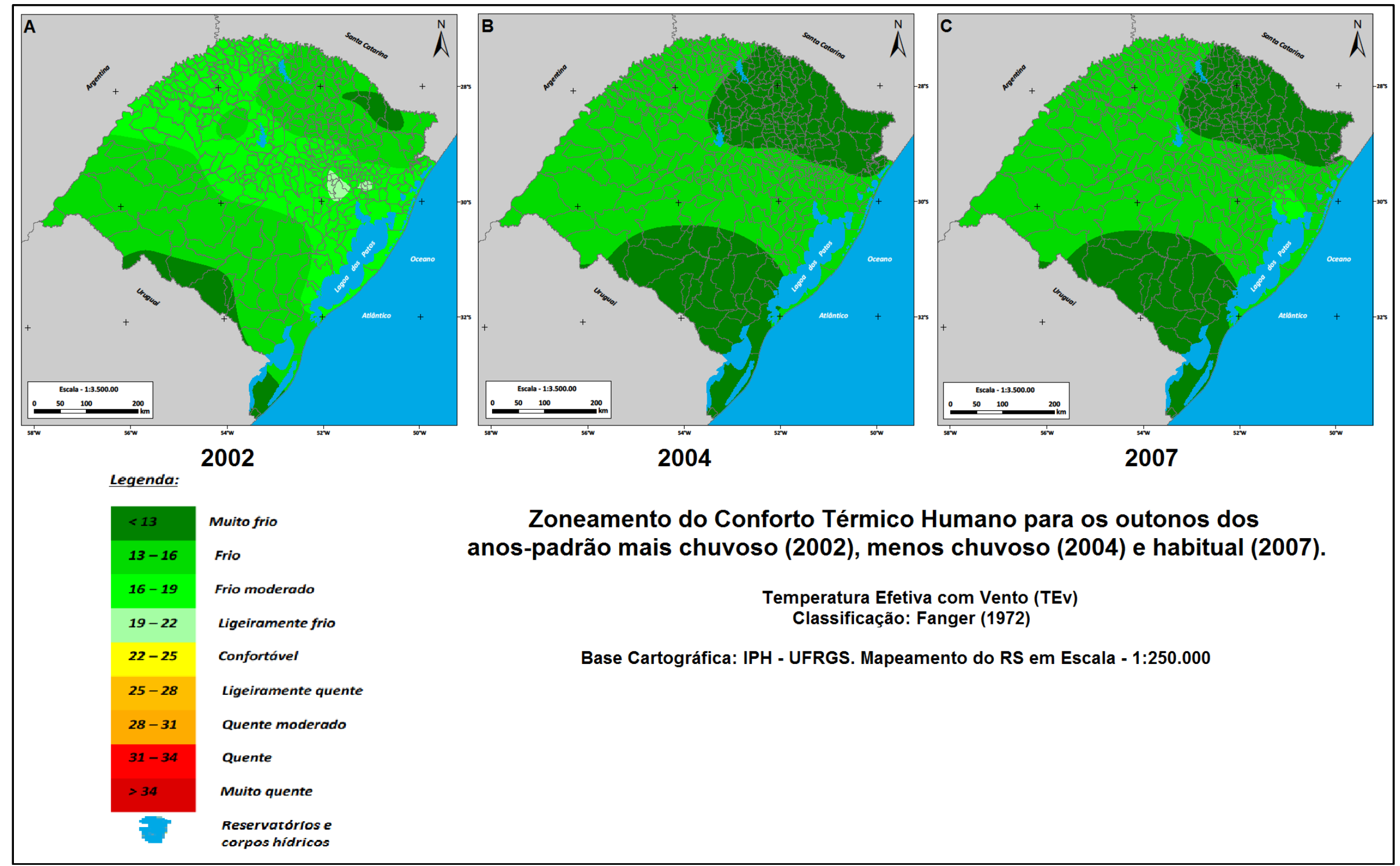

Figura 5: Mapas do Zoneamento do Conforto Térmico para o outono dos anos-padrão 2002, 2004 e 2007. Org.: GOBO, J. P. A. (2014). 


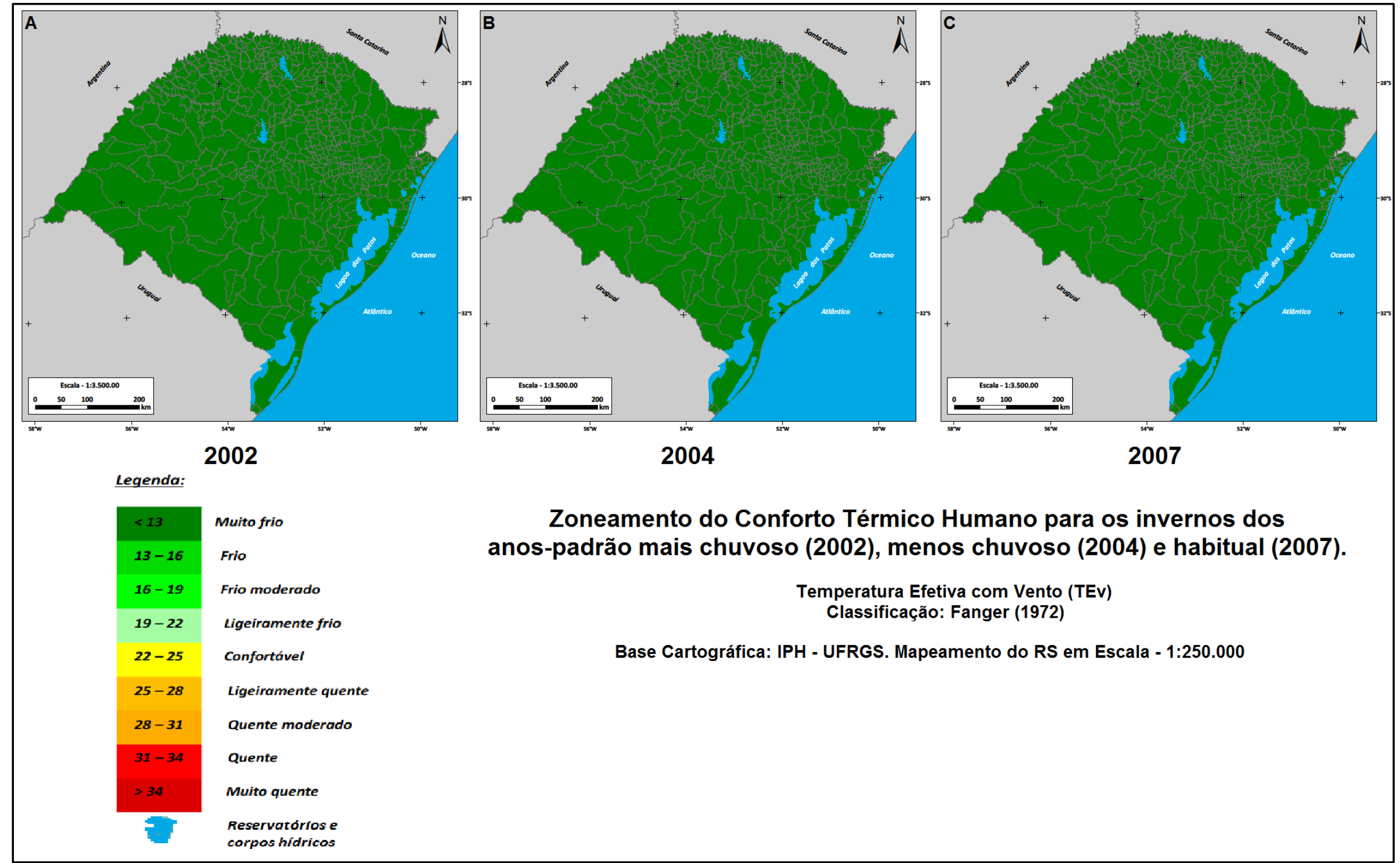

Figura 4: Mapas do Zoneamento do Conforto Térmico para os invernos dos anos-padrão 2002, 2004 e 2007. Org.: GOBO, J. P. A. (2014) 


\section{Zoneamento médio sazonal dos Anos-Padrão}

Ao se fazer uma análise dos zoneamentos do conforto térmico para primavera, verão, outono e inverno dos três anos- padrão analisados (2002, 2004 e 2007), notou-se a grande diferença entre as situações de outono e inverno, em relação aos zoneamentos da primavera e do verão.

Em parte, isso pode ser associado ao uso de dois índices de conforto térmico diferentes (TR, primavera e verão; TEv, outono e inverno), sendo que um deles utiliza a variável vento na sua equação (TEv) e o outro não (TR). Porém, em função do que já foi justificado na metodologia, a utilização do vento no cálculo do conforto térmico para os meses de primavera e verão no Rio Grande do Sul não é determinante, pois trata-se dos meses com menor frequência de ventos, na média, para a area de estudo. Sendo assim, a maior homogeneidade apresentada no zoneamento dos invernos dos anos-padrão bem como nos outonos dos anos-padrão habituais e menos chuvosos, deve-se a influência da dinâmica atmosférica regional, a qual será tratada no próximo capítulo.

No entanto, pode-se inferir para o zoneamento do conforto térmico das estações de primavera e verão dos três anos-padrão que a distribuição das faixas de sensação térmica classificadas nesses zoneamentos estão relacionadas à possível influência de controles climáticos, tais como a altitude, a continentalidade, a maritimidade e a latitude das diferentes regiões do Rio Grande do Sul.

Para tanto, como foi exposto na metodologia desta pesquisa, foi elaborado o zoneamento sazonal médio dos três anos-padrão estudados, a partir da elaboração de quatro mapas de zoneamento do conforto térmico do Rio Grande do Sul referentes às três primaveras, aos três verões, aos três outonos, através da sobreposição destes, o que resultou nos quatro mapas de zoneamento médio sazonal dos anos-padrão (Figura 7).

\section{$\checkmark \quad$ Outono;}

O zoneamento do conforto térmico médio dos três outonos estudados apresenta apenas duas faixas de sensação térmica classificadas, tanto quanto o zoneamento dos outonos dos anos-padrão menos chuvosos e habituais (2004 e 2007 respectivamente).

As faixas de sensação térmica em questão são as de "Muito Frio" e "Frio Moderado", sendo a primeira restrita à metade sul do Estado, ocupando parte do litoral sul e da campanha gaúcha, na região da fronteira com o Uruguai, e a serra do nordeste, ocupando também uma pequena parcela do planalto.

A faixa de sensação térmica de "Frio Moderado", abrange todo o oeste e noroeste do Rio Grande do Sul, a região central do Estado e a faixa litorânea, desde o sul da Lagoa dos Patos até a divisa com Santa Catarina.

Novamente nota-se a influência dos controles geográficos na disposição das duas faixas de sensação térmica classificadas no zoneamento médio do outono dos anos-padrão.

\section{$\checkmark \quad$ Inverno;}

O zoneamento médio dos invernos dos três anos-padrão estudados mostra-se completamente homogêneo, como esperado, com todo o Rio Grande do Sul inserido na faixa de sensação térmica de "Muito Frio", com índice TEv médio menor que $13^{\circ} \mathrm{C}$, o que, de fato, não se assemelha aos demais zoneamentos realizados, em virtude da possível não influência dos fatores geográficos na determinação da distribuição das faixas classificadas. 


\section{$\checkmark \quad$ Primavera;}

A análise do zoneamento do conforto térmico para as três primaveras referentes aos três anos-padrão estudados mostra-se bastante semelhante à primavera do ano-padrão habitual (2007), apresentando três faixas de sensação térmica definidas como "Frio", "Frio Moderado" e "Ligeiramente Frio".

Destas, a que ocupa a maior área do Estado é a de "Frio Moderado", com índice TR médio variando entre $16^{\circ} \mathrm{C}$ e $19^{\circ} \mathrm{C}$ e ocupando praticamente todo o Rio Grande do Sul, com exceção da região do vale do rio Uruguai, no noroeste do estado, e da região da serra de nordeste, as quais estão classificadas na faixa de "Ligeiramente Frio" e "Frio", respectivamente.

\section{$\checkmark \quad$ Verão;}

O zoneamento do verão, por sua vez, apresenta-se muito semelhante ao zoneamento do verão para o ano-padrão mais chuvoso (2002), também com três faixas de sensação térmica classificadas, sendo estas a de "Frio Moderado", "Ligeiramente Frio" e "Confortável".

Nota-se nesse zoneamento, assim como nos demais zoneamentos para os verões dos anos-padrão, uma interessante relação entre o relevo, a continentalidade e a latitude das diferentes regiões do Rio Grande do Sul, o que é bastante determinante na distribuição das faixas classificadas.

As áreas "mais frias", do ponto de vista do conforto térmico, estão restritas às regiões mais altas do estado, na serra de nordeste, próximas à divisa com o estado de Santa Catarina, classificadas na faixa "Frio Moderado", com índice TR médio entre $16^{\circ} \mathrm{C}$ e $19^{\circ} \mathrm{C}$. Toda a faixa central do Rio Grande do Sul, bem como o oeste do estado e parte da faixa litorânea, onde a altitude não passa dos $300 \mathrm{~m}$, está classificada na faixa de "Confortável", com índice TR médio entre $22^{\circ} \mathrm{C}$ e $25^{\circ} \mathrm{C}$. A maior parte do Estado está classificada dentro da faixa de sensação térmica de "Ligeiramente Frio", com índice TR médio oscilando entre $19^{\circ} \mathrm{C}$ e $22^{\circ} \mathrm{C}$, o que pode se associar à altitude média dessas regiões (entre $300 \mathrm{~m}$ e $700 \mathrm{~m}$ ) e a disposição latitudinal delas, no que diz respeito à parcela sul do Estado.

Após a análise da sobreposição dos zoneamentos para as quatro estações do ano dos três anos-padrão, fica evidente o controle dos atributos climáticos na distribuição das faixas de conforto térmico em todas as estações do ano, com exceção do inverno, a qual deve suas características bioclimáticas aos padrões da dinâmica atmosférica regional. 


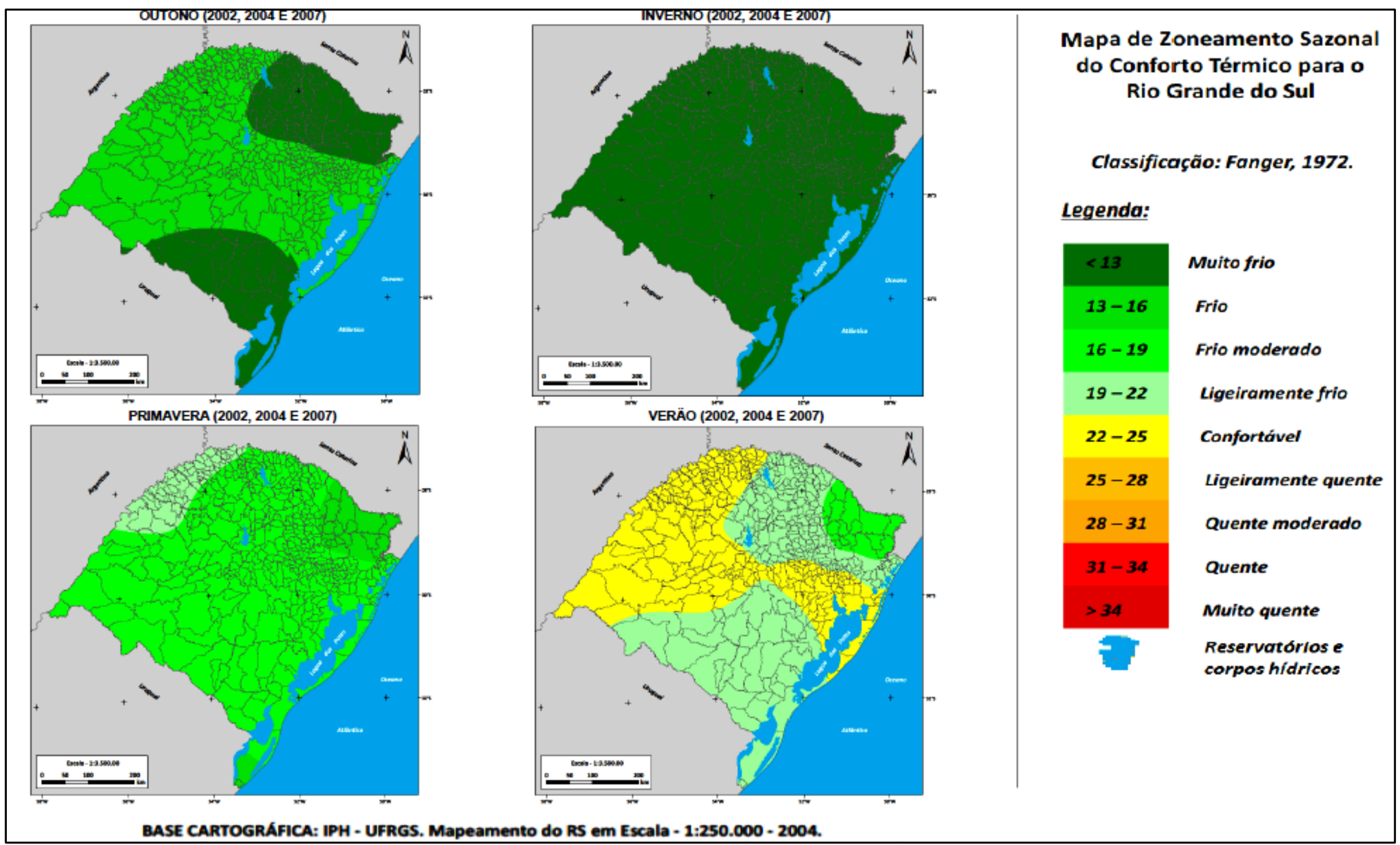

Figura 7: Mapas do Zoneamento do Conforto Térmico sazonal para os anos-padrão 2002, 2004 e 2007 sobrepostos. Org.: GOBO, J. P. A. (2014). 


\section{CONSIDERAÇÕES FINAIS}

No que se refere ao zoneamento do conforto térmico para os anos-padrão estabelecido como habitual (2007), mais chuvoso (2002) e menos chuvoso (2004), observouse que a disposição das zonas classificadas nas estações de primavera, verão e outono foram influenciadas pelos atributos geográficos, tais como o relevo (altitude), a continentalidade e a maritimidade e a latitude. Estes determinaram a disposição das zonas classificadas de maneira semelhante nas respectivas estações climáticas de cada ano analisado.

O zoneamento do conforto térmico para os anos-padrão não revelou influência dos fatores geográficos no zoneamento dos invernos dos três anos-padrão, uma vez que houve, assim como no zoneamento da série de 30 anos, uma homogeneização da sensação térmica classificada, em todo o Estado, na faixa de "Muito Frio".

Em relação ao ano-padrão mais chuvoso, este se mostrou mais frio do ponto de vista do zoneamento da primavera e do verão. O outono do ano-padrão mais chuvoso, por sua vez, apresentou classes de conforto térmico mais próximas da zona de conforto do que os demais outonos estudados, ao contrário do inverno, que foi totalmente predominado pela classe mais fria.

O ano-padrão menos chuvoso mostrou, assim como o ano mais chuvoso, uma amenização nos valores do conforto térmico, com o outono e a primavera mais homogêneos quanto a distribuição das faixas de conforto, e o verão com poucas zonas nas faixas mais quentes. Por outro lado, o inverno novamente se mostrou homogêneo, com uma só classe predominante.

$\mathrm{O}$ ano-padrão habitual mostrou-se o mais quente dos três, tendo o verão apresentado, em sua maioria, o predomínio de zonas mais quentes, no território do Rio Grande do Sul. Todavia, o outono e o inverno mostraram-se igualmente homogêneos, como os analisados nos anos anteriores.

Assim, o zoneamento do conforto térmico na área de estudo é influenciando por controles climáticos como por exemplo, altitude, continentalidade e maritimidade, nas estações de primavera e verão e pela dinâmica climática regional nas estações de outono e inverno.

\section{AGRADECIMENTOS}

À Coordenação de Aperfeiçoamento de Pessoal de Nível Superior (CAPES) pela concessão de bolsa de estudo de mestrado.

\section{REFERÊNCIAS BIBLIOGRÁFICAS}

RIO GRANDE DO SUL. Secretaria da Coordenação e Planejamento. Atlas socioeconômico do Rio Grande do Sul. Porto Alegre: SCP, 2010. Impresso e on line, ed. atualizada. www.scp.rs.gov.br/atlas/

BERLATO, M.A; FONTANA, D.C. El Niño e La Niña: impactos no clima, na vegetação e na agricultura do Rio Grande do Sul: aplicações de previsões climáticas na agricultura. Porto Alegre: ed.da UFRGS, 2003.110p.

CHANGNON, S. A.; PIELKE JUNIOR, R. A.; CHANGNON, D.; SYLVES, R. T.; PULWARTY R.; Human Factors Explain the Increased Losses from Weather and Climate Extremes. Bulletin of the American Meteorological Society, Vol. 81, nr. 3, 437-442, 2000. 
COSTA, E. R. ; SARTORI, M. G. B ; FANTINI, V., Estudo da relação entre eventos El-Niño - La-Niña e ocorrência de ondas de frio na região de Santa Maria-RS. Boletim Gaúcho de Geografia, v. 32-33, p. 263-276, 2008.

FANGER, P.O. Thermal comfort, analysis and application in environmental engineering. New York: McGraw Hill, 1972.

GOLDEN, J. S.; HARTZ, D.; BRAZEL, A.; LUBER, G.; PHELAN, P.; A biometeorology study of climate and heat-related morbidity in Phoenix from 2001 to 2006. International Journal of Biometeoroly, nr. 52, 471-480, 2008.

INSTITUTO BRASILEIRO DE GEOGRAFIA E ESTATÍSTICA. Ministério do Planejamento, Orçamento e Gestão. Coordenação de Agropecuária. Cidades. Rio de Janeiro: IBGE, 2014.

MAIA, J. A.; GONÇALVES, F. L. T. Uma análise do conforto térmico e suas relações meteorotrópicas na cidade de São Paulo - parte 1. Anais: XII Congresso Brasileiro de Meteorologia, p. 305-314, Foz de Iguaçu, 2002.

MATZARAKIS, A.; MAYER, H., Heat stress in Greece. International Journal Biometeoroly. 41:34-39, 1997.

MISSENARD, H. Equivalence Thermique dês Ambience. Chaleur et Industrie, 24; p.159-183. 1948.

MONTEIRO, C. A. F. O clima da região Sul. In: CATALDO, D. M. (Org.). Geografia do Brasil, Grande Região Sul. Rio de Janeiro: IBGE, p. 117-169, 1963.

MONTEIRO, C. A. F. A Frente Polar Atlântica e as Chuvas de Inverno na Fachada Sul-Oriental do Brasil (Contribuição metodológica à análise rítmica dos tipos de tempos no Brasil.) Série Teses e Monografias, nำ. São Paulo: Instituto de Geografia/USP, 1969.

MONTEIRO, C. A. F. Análise rítmica em climatologia - problemas da atualidade climática em São Paulo e achegas para um programa de trabalho. Revista IGUSP. São Paulo. [s./v.], [s./n.], p. 1-21, 1971.

MONTEIRO, C. A. F. Teoria e Clima Urbano. São Paulo: Instituto de Geografia/USP, 181p. (Série Teses e Monografias, 25). 1976.

MONTEIRO, C. A. F. A dinâmica climática e as chuvas no estado de São Paulo. Rio Claro: UNESP- IGCE, 2000. CD-ROM.

MONTEIRO, L.; ALUCCI, M. Procedimentos para quantificação de variáveis para análise termo-fisiológica em espaços abertos. In: VIII ENCAC, 2005, Maceió. Anais... Antac, 2005.

MONTEIRO, L. M.; ALUCCI, M. P. Questões teóricas de conforto térmico em Questões teóricas de conforto térmico em espaços abertos: consi deração histórica, discussão do estado da arte e proposição de classificação de modelos... Ambiente Construído, v. 7, p. 43-58, 2007.

MONTEIRO, L. M.; ALUCCI, M. P. Comparação Cruzada Entre Pesquisas Laboratoriais e de Campo em Conforto Térmico em Espaços Urbanos Abertos. Ambiente Construído, Porto Alegre, v. 10, n. 4, p. 79-101, out./dez. 2010.

MOURA, M. O.; ZANELLA, M. E., Escolha de "anos- padrão" para o estudo do conforto térmico em Fortaleza, CE: verificação de critérios. REVISTA GEONORTE, Edição Especial 2, V.1, N.5, p.547 - 560, 2012.

RUOSO, D.; SARTORI, M. G. B.; WOLLMANN, C. A.; COSTA, E. R. Respostas locais à circulação regional em Santa Maria e Santa Cruz do Sul: Uma análise de normais climatológicas de temperatura e precipitação. In: SIMPÓSIO BARSILEIRO DE 
CLIMATOLOGIA GEOGRÁFICA, 7. Rondonópolis: UFMT, 2006. 20-25 ago.Anais... 1CD-ROM.

SARTORI, M. G. B., As variações pluviométricas e o regime das chuvas na região central do Rio Grande do Sul. Rio Claro, Boletim de Geografia Teorética, v. 23, p. 72-80, 1993.

SARTORI, M. G. B. A dinâmica do clima do Rio Grande do Sul: indução empírica e conhecimento científico. Revista Terra Livre, São Paulo, v. 1, no . 20, p. 27-49, jan./jul. 2003.

SECRETARIA ESTADUAL DO MEIO AMBIENTE. Governo do Estado do Rio Grande do Sul. Regiões Hidrográficas do Rio Grande do Sul. Disponível em: www.sema.rs.gov.br. Acesso em: 19 de fev. 2010.

SORRE, M. Le Climat. In: SORRE, M. Les Fondements de la Géographie Humaine. Paris: Armand Colin, 1951. Chap. 5, p.13-43

SUPING, Z.; GUANGLIN, M.; YANWEN, W.; JI, L. Study of the relationships between weather conditions and the marathon race, and of meteorotropic effects on distance runners. International Journal of Biometeorology, 36, 63-68, 1992.

WOLLMANN, C. A.; SARTORI, M. G. B., Frequência mensal e sazonal da participação de sistemas atmosféricos no verão do Rio Grande do Sul: análise sobre três casos típicos (1986/1987, 1997/1998 e 2004/2005). Ciência e Natura, UFSM, 31 (1): 141 - 161, 2009. 